Revista de Economia Política, vol. 25, № 3 (99), pp. 190-208, julho-setembro/2005

\title{
A substituição de importações no Brasil entre 1995 e 2000
}

\author{
AN A MARIA DE PAIVA FRANCO* \\ RENATO BAUM AN N**
}

Import substitution in Brazil between 1995 and 2000. This work estimates the import substitution process in Brazilian industrial sectors in a recent period and evaluates whether it is occurring naturally or is in part induced by some kind of external commercial policy. An index to measure import substitution was calculated for forty nine sectors of industry. A regression analysis with this index against effective tariffs and real effective exchange rate, during the period 1995-2000, shows that these variables (effective tariffs and real effective exchange rates) did affect the substitution index. From 1999 on, the influence of the exchange rate over the import substitution index was greater than the influence of the effective tariff, suggesting that the process of import substitution post the Brazilian currency depreciation occurred in 1999 contains elements that characterizes it as a "natural" process.

Key-words: Impost Substitution; Effective Tariffs; Currency Depreciation.

JEL Classification: F13; F14

\footnotetext{
* Professora do Departamento de Economia da Faculdade de Economia, Administração e Contabilidade de Ribeirão Preto - Universidade de São Paulo. M estre em economia pela Universidade de Brasília; doutoranda pelo Instituto de Pesquisas Econômicas da Universidade de São Paulo. E-mail: anafranco@usp.br.

** professor do Departamento de Economia da UnB e do Instituto Rio Branco. D Phil pela Universidade de Oxford. Diretor do Escritório da CEPAL no Brasil. E-mail: rbaumann@cepal.org.br. Submetido: março 2004: A ceito outubro 2004.
} 


\section{INTRODUÇÃO}

A discussão sobre a necessidade de se diminuir a vulnerabilidade externa do país, através de superávits crescentes na balança comercial e de um adensamento da cadeia produtiva de alguns setores chave da economia, tem sido recorrente em debates nos âmbitos governamental, empresarial e junto a entidades ligadas à indústria e ao comércio exterior (M elo, Rios e Gutierrez, 2001; Rosa, 2001; Alem, Barros e Giambiagi, 2002). Há um consenso de que o país precisa aumentar a competitividade dos seus produtos no mercado interno e no mercado mundial, e as divergências quanto ao grau de intervenção do Estado neste processo são muito grandes ${ }^{1}$.

N o presente trabalho são analisados dados da economia brasileira nos anos 1995-2000, quando se mostram indícios de um processo de substituição de importações em alguns setores da economia brasileira a partir da desvalorização do Real em 1999 (M oreira e Puga 2001, Levy e Serra 2002). O objetivo, é constatar a existência de um processo de substituição de importações, e verificar se o mesmo ocorre "espontaneamente" ou se é um resultado de políticas intervencionistas do governo. Para atingir o objetivo proposto, foi feito ajuste de um modelo de regressão linear no conjunto de dados da indústria usando os níveis tarifários e cambiais como variáveis explicativas, e como variável resposta uma medida de substituição de importações.

\section{O QUE SE ENTENDE POR SUBSTITUIÇÃO DE IM PORTAÇÕES}

0 termo "substituição de importações" bem como "proteção" e "promoção" nos remetem aos debates em torno das políticas comerciais dos países em desenvolvimento na segunda metade do século XIX, e suas definições muitas vezes são ambíguas.

Tavares (1977) define substituição de importações como todo um processo de desenvolvimento que, respondendo às restrições do comércio exterior - como aconteceu com os países do Cone Sul nas quatro décadas que se seguem ao pós-Guerra - procurou repetir aceleradamente, em condições históricas distintas, a experiência de industrialização dos países desenvolvidos.

O objetivo seria a geração de uma economia suficientemente flexível, diversificada, capaz de superar choques, poder responder a estes e realmente criar oportunidades para o crescimento, e poder, por conta própria, gerar continuamente crescimento e bem-estar para a sua população. A lógica básica da estratégia de substituição de importações é que essa transformação das economias em desenvolvimento demanda proteção em relação à concorrência com produtos importados (Bruton, 1989, p. 1.603).

\footnotetext{
${ }^{1}$ Para uma discussão em torno de um novo perfil da política industrial a ser traçado no Brasil ver Barros e Goldstein (1997); Alem, Barros e Giambiagi (op. cit.).
} 
O peracionalmente a definição de substituição de importações dada por Chenery, citado por Diaz-A lejandro (1975), é: a proporção da oferta total de um determinado bem obtido por importações no lugar de produção doméstica pode declinar (ocorre substituição de importações) e isso pode ser devido a: (1) uma tarifa passa a incidir sobre as importações do produto (2) uma desvalorização torna as importações mais caras, ou (3) outras razões, tais como interrupção das operações de comércio por motivos de guerra.

Segundo Desai (1969) há dois tipos alternativos de medidas de substituição de importações: (1) aquelas envolvendo referências a uma noção de optimalidade e (2) aquelas que simplesmente descrevem as mudanças no padrão de importações e de produção doméstica.

$\mathrm{N}$ ão se deve considerar o termo substituição de importações uma operação simples e limitada de retirar ou diminuir componentes da pauta de importações para substituí-los por produtos nacionais. Isto poderia levar à compreensão de que o objetivo de tal estratégia seria a eliminação de todas as importações e 0 alcance da autarquia. No caso do processo de substituição de importações, no lugar dos bens substituídos aparecem outros e, à medida em que avança o processo ocorre um aumento da demanda derivada por importações (de produtos intermediários e bens de capital) que pode resultar de fato em maior dependência do exterior. Assim, a substituição "aparente" pode estar escondendo a essência do fenômeno:

1. M esmo que não haja uma redução no quantum ou na participação de alguns produtos na pauta, pode estar ocorrendo um processo de substituição através do aumento da participação doméstica devido a oferta interna crescente, com redução do coeficiente de importações da economia.

2. Com o aparecimento de novos produtos no mercado internacional, a análise de comparação da pauta de importações entre períodos distintos pode ficar prejudicada. É preciso observar, por exemplo, se o aumento das importações de um determinado item da pauta vem deslocando a produção interna ou se trata-se de um novo produto, cuja produção interna é inexistente.

3. A diminuição da importação de alguns produtos pode decorrer de algum fator tal como sanção comercial, algum tipo de política discriminatória ou outros fatores do tipo. Só terá ocorrido substituição "real" de importações se houver um estímulo à produção interna.

4. A substituição "real" ou "efetiva" é geralmente muito menor do que a "aparente" que se visualiza com a diminuição da importação de certos itens. A produção de um determinado bem apenas "substitui" uma parte do valor agregado que antes era gerado fora da economia. A ssim, pode ser que haja um aumento em termos dinâmicos da demanda derivada de importações em um grau superior à economia de divisas que se obteve com a produção substitutiva.

Portanto, ao se falar em promover a substituição de importações deve estar subentendido que: (1) a produção interna deve ser estimulada e (2) o processo 
pode levar a uma piora na balança comercial e a uma maior dependência externa, tanto no caso de haver necessidade de se importar bens intermediários e de produção quanto pelo efeito demanda derivada do crescimento da renda' induzido pelo aumento da produção interna dos setores beneficiados (Tavares, 1977).

\section{UM BREVE HISTÓRICO DAS MUDANÇASNO REGIME DE COMÉRCIO DO BRASIL: DA RESERVA DE MERCADO À ABERTURA DA ECONOMIA}

N este artigo fazemos uma distinção entre processos de substituição de importações de tipo "induzido" e "espontâneo".

A substituição que aqui chamamos de "induzida" é a que pode ser obtida através do uso de políticas intervencionistas para estimular a produção interna de um determinado produto que o país importa. Um exemplo é a substituição de importações naqueles setores em que - além dos preços favoráveis - há o efeito de barreiras a importações competitivas. A substituição "espontânea" de importações, por outro lado, é a que ocorre naturalmente em decorrência de uma mudança nos preços relativos do produto nacional frente ao importado, tornando o produto nacional mais barato. Esta mudança dos preços relativos pode estar associada tanto a maiores ganhos de produtividade na indústria nacional quanto a uma depreciação da moeda nacional frente à moeda estrangeira, o que confere maior competitividade ao produto fabricado internamente.

$\mathrm{N}$ o modelo de substituição de importações vigente no Brasil até o final da década de 1980 inúmeros instrumentos de política eram utilizados para impedir a entrada dos produtos estrangeiros, tais como licenças para importação, quotas, leilões cambiais, e tarifas. D esde os últimos anos daquela década, a política de comércio exterior passou por grandes mudanças, com um processo de abertura da economia. Esse processo ganhou força na década seguinte, quando uma série de acordos comerciais foram estabelecidos, sendo o mais notável a criação do M ercosul em 1991.

A política de redução das barreiras de importação foi implementada em três etapas (Kume, Piani e Souza, 2000, p.1-10), podendo-se diferenciar entre os períodos de 1988-89, 1990-93 e a partir de 1994. Houve um certo recuo no processo de abertura da economia no período 1995-1998 após a crise do M éxico em dezembro de 1994, quando o financiamento do déficit comercial crescente (decorrente da valorização da taxa de câmbio e da ampliação da abertura comercial no início do Plano Real) tornou-se inviável. 0 aspecto relevante a enfatizar é que as barreiras não-tarifárias mais importantes foram retiradas em 1990, o que fez com que praticamente durante toda a década as importações fossem afetadas principalmente pelas tarifas e pela taxa de câmbio.

N uma primeira fase, correspondendo a $1988-89$, houve duas reformas tarifárias (junho de 1988 e setembro de 1989) que reduziram o componente redundante da tarifa nominal, sem que isto afetasse de forma significativa o volume de 
importações. No período 1990-1993 foram eliminadas as barreiras não-tarifárias e os regimes especiais de tributação. Em seguida foi implementado um cronograma de redução gradual das tarifas de importação. Em 1994, ocorreram as reduções tarifárias promovidas no início do Plano R eal, com o objetivo de controlar os preços internos através de uma maior competição externa. N o período 1995-1998 houve um retrocesso no programa de liberalização comercial, com a elevação de tarifas de alguns bens de consumo e a reintrodução de dificuldades administrativas na importação² (K ume, Piani e Souza, 2000, p. 3-4). H ouve elevação das alíquotas de importação de automóveis, motocicletas, bicicletas, tratores, el etroel etrônicos de consumo, tecidos, cobertores e tênis, itens responsáveis pelas taxas de crescimento das importações. Paralelamente, para evitar aumentos dos preços domésticos, o governo reduziu as alíquotas de um grupo de insumos (Kume, Piani e Souza, 2000, p. 9).

O M ercosul - cuja tarifa externa comum passou a vigorar, no Brasil, em setembro de 1994 para a maior parte dos produtos, antecipando o cronograma anterior, previsto para janeiro de 1995 (Baumann, Rivero e Z avattiero, 1997) significou uma perda de autonomia na condução da política tarifária. Para implementar as medidas mencionadas acima o governo precisou incluir parte dos produtos na Lista de Exceção $\mathrm{N}$ acional do $\mathrm{M}$ ercosul, que foi posteriormente alterada por nova lista, com alíquotas válidas por um ano. De maneira geral, porém, a tarifa externa comum impediu maiores mudanças na estrutura tarifária, e o período 1995-1998 foi o que apresentou maior estabilidade das tarifas. Por fim, em novembro de 1997, o governo aumentou temporariamente as tarifas em 3 pontos de percentagem, como medida para reduzir o déficit em transações correntes diante da crise financeira internacional.

Pode-se dizer, porém, que o país seguiu de forma progressiva na redução de suas barreiras comerciais e chegou, já no final da década de 1990 a uma situação em que as barreiras ao comércio resumem-se basicamente às tarifas nominais estabelecidas, tendo sido estas reduzidas de modo gradual, atingindo níveis mais uniformes entre os setores. A Figura 1, construída com base nos dados sobre Tarifa Efetiva $M$ édia ponderada pelo valor adicionado de livre comércio, por setor, de 1987 a 1998, ilustra bem o processo descrito acima ${ }^{3}$.

Como mostra a Figura 1, de 1987 a 1994 ocorreram as principais reduções na tarifa efetiva média dos setores, bem como no desvio padrão, levando a um quadro de maior homogeneidade na proteção dada aos diferentes setores da economia e, portanto, à diminuição das distorções provocadas por essa proteção. A pós 1995 as M édias Tarifárias oscilaram um pouco para cima, mas permanece-

\footnotetext{
${ }^{2}$ Tais como a exigência de pagamento à vista nas compras externas com financiamento externo inferior a um ano, a criação de uma lista de produtos para as quais era exigida licença prévia de importação e a aplicação de salvaguardas.

${ }^{3}$ O ptou-se por omitir a representação gráfica relativa à evolução da Tarifa N ominal M édia por esta apresentar um comportamento muito semelhante ao da Tarifa Efetiva, sendo o grau de correlação entre as duas tarifas no período analisado igual a 0,87.
} 
ram no patamar de $18 \%$, no caso da Tarifa N ominal, e $20 \%$, no caso da Tarifa Efetiva (Kume, Piani e Souza, 2000, p. 11 e 16)

A preservação desses níveis de proteção, associada ao desempenho da produção, permite supor que existiu um contexto propício a uma "indução potencial" de substituição de importações via proteção comercial ao longo da década de 1990. Para verificar essa hipótese, é necessário quantificar o processo de substituição de importações.

\section{METODOLOGIA}

\subsection{M ensuração do processo de substituição de importações}

Existem vários métodos para se fazerem os cálculos estatísticos da "substituição de importações" (D esai, 1969). As várias medidas de substituição de importações permitem associar os efeitos das políticas comerciais e a relação balança comercial/ produção nacional em uma indústria ou setor e estão baseadas nos dados de importação e oferta de cada mercadoria em dois períodos de tempo subseqüentes.

$\mathrm{N}$ este artigo usaremos a seguinte notação: para uma mercadoria a, a importação e oferta nos períodos 1 e 2 , serão identificados por

$M \mathrm{a}_{1}=$ importação da mercadoria a no Período 1

$\mathrm{Sa}_{1}=$ oferta da mercadoria a no Período 1

$M \mathrm{a}_{2}=$ importação da mercadoria a no Período 2

$\mathrm{Sa}_{2}=$ oferta da mercadoria a no Período 2

Se $M a_{2} / S a_{2}<M a_{1} / S a_{1}$ houve substituição de importações no Período 2. A partir daí, são definidas duas medidas de substituição de importações, que identificamos como Variante 1 e Variante 2.

Variante 1

Uma maneira de se medir a substituição de importações em termos de comparações de situações reais é tomar a diferença entre as taxas observadas de disponibilidade de importações nos dois períodos. Pode-se tomar tanto a mudança absoluta (para a V ariante 1a) como a variação percentual (para a Variante 1b) das taxas. Isso permite construir duas medidas, indicadas por $\mathrm{SI}_{1 a}$ e $\mathrm{SI}_{1 b}$ :

$\mathrm{SI}_{1 \mathrm{a}}=\mathrm{M}_{2} / \mathrm{S}_{2}-\mathrm{M}_{1} / \mathrm{S}_{1}(1)$

$\mathrm{Sl}_{1 \mathrm{~b}}=\left(\mathrm{M}_{2} / \mathrm{S}_{2}-\mathrm{M}_{1} / \mathrm{S}_{1}\right) / \mathrm{M}_{1} / \mathrm{S}_{1}(2)$

$\mathrm{SI}_{1 a}$ éa medida de substituição de importações pela $V$ ariante la: há substituição de importações em um determinado setor da indústria quando $M_{2} / S_{2} M_{1} / S_{1}<0$.

$\mathrm{N}$ a comparação entre dois setores, terá tido maior substituição de importações aquele que tiver o menor índice $\mathrm{SI}_{1 \mathrm{a}}$.

$\mathrm{SI}_{1 b}$ é a medida de substituição de importações pela Variante $1 \mathrm{~b}$, e trata-se de apenas uma versão em termos relativos de $\mathrm{SI}_{1 a}$. $\mathrm{H}$ á substituição de importa- 
ções quando $\left(M_{2} / S_{2} M_{1} / S_{1}\right) / M_{1} / S_{1}<0$, isto é, quando $S_{1 b}$ for menor que zero. Da mesma forma que a variante $\mathrm{Sl}_{1 \mathrm{a}}$ o índice $\mathrm{Sl}_{1 \mathrm{~b}}$ apresenta 0 inconveniente de ser uma função decrescente do grau de substituição de importações dos diversos setores.

Valores negativos de $\mathrm{SI}_{1 \mathrm{a}}$ ou de $\mathrm{SI}_{1 \mathrm{~b}}$ indicam ter havido substituição de importações. Para usar esses índices nas análises de regressão descritas a seguir foi necessário transformá-los, fazendo $\mathrm{SI}_{i}=\mathrm{SI}(-1)$, de tal modo que um índice positivo indicasse substituição de importações, e esse processo será tão mais intenso quanto maior Sli.

\section{Variante 2}

De modo indireto, a substituição de importações pode ser definida como a diferença entre $o$ crescimento do produto com nenhuma mudança na taxa de importações e o crescimento efetivamente ocorrido.

Partindo-se da identidade básica:

$\mathrm{Q}+\mathrm{M} \equiv \mathrm{R}+\mathrm{D}+\mathrm{E}$

em que:

$Q=$ produção doméstica

$M=$ importações

$\mathrm{R}=$ demanda intermediária

$D=$ demanda doméstica final (incluindo acumulação de estoques)

$\mathrm{E}=$ exportações

tem-se a seguinte identidade para os valores incrementais:

$\Delta \mathrm{Q}+\Delta \mathrm{M} \equiv \Delta \mathrm{R}+\Delta \mathrm{D}+\Delta \mathrm{E}$

Se $S=Q+M=$ oferta total;

então $\Delta S=\Delta \mathrm{R}+\Delta \mathrm{D}+\Delta \mathrm{E}$

Seja $u_{1}=Q_{1} / S_{1}$ no ano base. Se $u_{1}$ permanecer fixo, a mudança na produção doméstica $\Delta \mathrm{Q}$ é dada por $\mathrm{u}_{1} \cdot \Delta \mathrm{S}$ ou $\mathrm{u}_{1} \cdot(\Delta \mathrm{R}+\Delta \mathrm{D}+\Delta \mathrm{E})$. Supondo que $\mathrm{u}_{1}$ mude para $u_{2}=Q_{2} / S_{2}$, a mudança na produção será dada por:

$\Delta \mathrm{Q}=\mathrm{u}_{1}(\Delta \mathrm{R}+\Delta \mathrm{D})+\mathrm{u}_{1}(\Delta \mathrm{E})+\left(\mathrm{u}_{2}-\mathrm{u}_{1}\right) \mathrm{S}_{2}(3)$

A relação ( 3 ) divide a produção interna adicional $(\Delta Q)$ em três partes:

$\mathrm{u}_{1}(\Delta \mathrm{R}+\Delta \mathrm{D})$, a parte destinada à demanda final e intermediária, sob a hipótese de que a participação da produção doméstica sob oferta total não se altera;

$\mathrm{u}_{1}(\Delta \mathrm{E})$, a parte destinada às exportações, assumindo-se $\mathrm{u}_{1}$ constante;

$\left(\mathrm{U}_{2}-\mathrm{u}_{1}\right) \mathrm{S}_{2}$ a mudança na oferta devida à variação na participação da produção doméstica na oferta total.

0 termo (c) é a medida da produção doméstica adicional que resultaria exclusivamente de uma mudança na participação da produção doméstica na oferta total. Essa produção adicional, se dividida pela variação da produção interna $(\Delta Q)$, torna-se a variante $2\left(\mathrm{SI}_{2}\right)$ para se medir a substituição de importações:

\section{$\mathrm{SI}_{2}=\left(\mathrm{u}_{2}-\mathrm{u}_{1}\right) \mathrm{S}_{2} /(\Delta \mathrm{Q})(4)$}

Segundo esta medida, há substituição de importações quando $\left(u_{2}-u_{1}\right) S_{2} /$ $(\Delta \mathrm{Q})$ for maior que zero (isto é, quando ocorrer $\mathrm{Sl}_{2}>0$ ). 
Teoricamente (Desai, 1968) as medidas $\mathrm{SI}_{A}, \mathrm{Sl}_{B}$ e $\mathrm{SI}_{2}$ - todas baseadas na noção de mudanças nas taxas de disponibilidade de importação com relação ao ano base - devem mostrar a mesma direção de mudança, isto é, se ocorreu ou não substituição de importações. Porém, a magnitude dos ef eitos da substituição de importações e o ranking dos setores podem variar segundo a medida adotada.

As estimativas usando as medidas $\mathrm{SI}_{B}$ e $\mathrm{SI}_{2}$ não se mostraram adequadas para os propósitos deste trabalho: (1) as variações observadas em $\mathrm{SI}_{\mathrm{B}}$ deveram-se em grande parte à ponderação que esta medida recebe (1/ (M 1/S1)), e não puderam ser explicadas pelas variáveis câmbio e tarifa; (2) a medida $\mathrm{SI}_{2}$ mostrou grandes discrepâncias com os resultados de $\mathrm{SI}_{A}$ e $\mathrm{SI}_{B}$, devido a que o valor da produção interna em alguns setores (a preços constantes de 1998) decresceu entre dois períodos, indicando ter ocorrido um processo de substituição de importações quando, na realidade, o que houve foi uma inversão do sinal do denominador deste índice (Q 2 - Q 1 ).

Em vista disso, o índice de substituição de importações utilizado neste trabalho foi a medida $\mathrm{SI}_{\mathrm{A}}$.

Utilizando-se a base de dados de M oreira e Puga (op. cit.), foram calculadas as medidas $\mathrm{SI}_{\mathrm{A}}$ para os intervalos 1989-1994, 1994-1998, 1998-2000, e 19892000 para sete categorias de uso (Q uadro 1).

A escolha desses períodos está associada às fases do processo de abertura da economia brasileira a partir do final da década de 1980. N o primeiro intervalo, 1989-1994, ocorreram as principais alterações no regime de comércio e a maior redução das barreiras tarifárias. 0 segundo intervalo, 1994-1998, é marcado por um leve retrocesso no processo de abertura (ver Figura 1). 0 período 1998-2000 traz um novo ingrediente para a análise dos resultados do comércio exterior do país: a desvalorização do Real em janeiro de 1999. A lém disso, os resultados encontrados para este período permitem fazer um paralelo com os resultados encontrados por M oreira e Puga (op.cit.). 0 cálculo dos índices de $\mathrm{SI}_{A}$ para 0 intervalo 1989-2000 é importante também por relacionar dois períodos que diferem bastante quanto à política externa do país: toma como base 0 ano de 1989, quando ainda prevaleciam entraves ao comércio, e compara com o ano 2000, em que a economia apresenta maior grau de abertura ao comércio e maior competitividade, derivada da variação cambial.

N o Q uadro 1 observa-se que no período 1989-1994 não houve substituição de importações em qualquer das categorias consideradas. A o contrário, a proporção das importações sobre a oferta total aumentou no período, reduzindo a participação relativa da produção interna na oferta total. Isto vai de acordo com o que seria esperado, pois o período é marcado pela grande exposição da economia à concorrência externa, pela apreciação do Real, e pelos efeito-preço e efeito-riqueza derivados da estabilização dos preços internos.

N o período 1994-1998 não houve reversão da tendência de aumento da participação das importações sobre a oferta total. A única exceção diz respeito ao ocorrido no setor de bens intermediários, que apresentou no período uma leve substituição de importações. 
QUADRO 1: Valores da medida de substituição de importações $\mathrm{SI}_{\mathrm{A}}$ para a economia brasileira*

\begin{tabular}{|c|c|}
\hline Período e Grupo Industrial & $\mathrm{SI}_{\mathrm{A}}$ \\
\hline \multicolumn{2}{|l|}{ 1989-1994 } \\
\hline Bens de consumo duráveis & $-9,35$ \\
\hline Bens de consumo não-duráveis & $-4,25$ \\
\hline Bens intermediários & $-7,62$ \\
\hline Bens intermediários elaborados & $-10,42$ \\
\hline Bens de capital & $-21,80$ \\
\hline Equipamentos de transporte & $-14,79$ \\
\hline Total da indústria & $-9,82$ \\
\hline \multicolumn{2}{|l|}{ 1994-1998 } \\
\hline Bens de consumo duráveis & $-3,23$ \\
\hline Bens de consumo não-duráveis & $-0,24$ \\
\hline Bens intermediários & 0,81 \\
\hline Bens intermediários elaborados & $-2,40$ \\
\hline Bens de capital & $-13,93$ \\
\hline Equipamentos de transporte & $-1,37$ \\
\hline Total da indústria & $-1,94$ \\
\hline \multicolumn{2}{|l|}{$1998-2000$} \\
\hline Bens de consumo duráveis & 2,09 \\
\hline Bens de consumo não-duráveis & 0,84 \\
\hline Bens intermediários & $-1,07$ \\
\hline Bens intermediários elaborados & 2,34 \\
\hline Bens de capital & 0,44 \\
\hline Equipamentos de transporte & 4,94 \\
\hline Total da indústria & 1,55 \\
\hline \multicolumn{2}{|l|}{ 1989-2000 } \\
\hline Bens de consumo duráveis & $-10,49$ \\
\hline Bens de consumo não-duráveis & $-3,65$ \\
\hline Bens intermediários & $-7,88$ \\
\hline Bens intermediários elaborados & $-10,48$ \\
\hline Bens de capital & $-35,29$ \\
\hline Equipamentos de transporte & $-11,22$ \\
\hline Total da indústria & $-10,21$ \\
\hline
\end{tabular}

De acordo o Q uadro 1 no período 1998-2000 os setores que apresentaram substituição de importações, em ordem de importância, foram: equipamentos de transporte, intermediários elaborados, bens de consumo duráveis, bens de consumo não duráveis e bens de capital. 0 único setor que não apresentou substituição de importações no período segundo essa medida foi o setor de bens intermediários. O s resultados encontrados por M oreira e Puga (op.cit.) e aqueles aos 
quais se chega utilizando a medida $\mathrm{SI}_{\mathrm{A}}$ não são exatamente os mesmos, no que diz respeito à incidência e intensidade do processo de substituição de importações nos diversos setores no período ${ }^{4}$. Um resultado comum às duas abordagens entretanto é que, para a indústria de transformação como um todo, no período 1998-2000 ocorreu substituição de importações; o setor equipamentos de transporte foi o setor em que a substituição de importações foi maior, seguido pelo setor de bens intermediários elaborados; e o setor de bens intermediários não apresentou substituição de importações no período.

Comparando-se os anos de 1989 e 2000, os índices apresentados por todos os setores foram negativos, e com um valor absoluto muito grande. Em 1989 a Tarifa Efetiva M édia era da ordem de $70 \%$ na indústria de transformação, enquanto em 2000 esta mesma média estava em torno de 20\% (Figura 1). Q uando se mede a substituição de importações entre esses dois anos (1989-2000) os índices $\mathrm{SI}_{\mathrm{A}}$ indicam não ter ocorrido substituição de importações, e sim uma grande perda da participação da produção interna sobre a oferta total, em decorrência da maior exposição da economia à concorrência internacional.

Portanto, todo o efeito de uma substituição de importações nesse período está concentrado nos últimos anos da série, entre 1998 e 2000. Como neste período ocorreu uma significativa depreciação cambial em janeiro de 1999 sem que houvesse nenhum retrocesso no processo de redução das barreiras tarifárias (e por conseqüência, de manutenção do nível de proteção efetiva dada aos setores), pode-se supor que o processo de substituição de importações nesses anos tenha sido predominantemente espontâneo (isto é, resultado da competitividade da produção nacional associada à variação do câmbio).

\subsection{A relação entre tarifa, câmbio e substituição de importações}

Com o propósito de verificar se as alterações nos índices de substituição de importações nos diversos setores podem ser explicadas pelas variações ocorridas nos níveis tarifários e cambiais, foi feita uma análise dessas variáveis para alguns setores da indústria de transformação, para o período 1995-2000. 0 período anterior (1989-1994) não foi incluído na análise pois, como mostra o Quadro 1, neste período não houve substituição de importações. Além disso, como a desvaIorização significativa do Real ocorreu em 1999, é no intervalo 1995-2000 que encontramos os fenômenos que poderiam ter contribuído tanto para uma substituição de importações “induzida” (em resposta à política tarifária) quanto para

\footnotetext{
${ }^{4}$ Segundo M oreira e Puga (op.cit.), os setores que apresentaram substituição de importações foram, por ordem de importância (maior redução no coeficiente importações/consumo aparente) no período 1998-2000: equipamento de transporte (redução de 26,8\% no coeficiente de importação); intermediários elaborados (redução de $14 \%$ no coeficiente de importação); e bens de consumo não duráveis (redução de 10,5\% no coeficiente de importações). O s setores que apresentaram aumento do coeficiente de importações no período 1998-2000 foram: bens de consumo duráveis (aumento de $24 \%$ no coeficiente de importações); bens intermediários (aumento de 11,54\% no coeficiente de importações); e bens de capital (aumento de 3,5\% no coeficiente de importações).
} 
uma substituição de importações " natural" (como reflexo da depreciação cambial a partir de 1999).

O ptou-se por utilizar como indicador da taxa de câmbio o índice da Taxa de Câmbio Real Efetiva de acordo com Boletim Funcex de Câmbio $(1998,2000)$ calculado com base nas taxas de câmbio reais dos treze principais países com os quais o Brasil comercializa, ponderadas pela participação média de cada país na corrente de comércio (importação e exportação) do Brasil (Q uadro 2). Para o propósito deste trabalho, essa taxa apresenta uma vantagem com relação às paridades bilaterais com outras moedas ${ }^{5}$.

Quadro 2: Índice da Taxa de Câmbio Efetiva Real

$(\mathrm{R} \$$ / Cesta de13 moedas -agosto $1994=100)$

\begin{tabular}{ll}
\hline Ano & Índice \\
\hline 1995 & 96,1 \\
\hline 1996 & 99,1 \\
\hline 1997 & 94,6 \\
\hline 1998 & 99,8 \\
\hline 1999 & 116,4 \\
\hline 2000 & 107,2 \\
\hline
\end{tabular}

Fonte: Até 1997 Boletim Funcex do Câmbio (1998),

de 1998-2000 Boletim Funcex do Câmbio (2002).

Para analisar a influência das variáveis câmbio e tarifa efetiva sobre o índice de substituição de importações, foi feita uma análise de regressão utilizando informações do período 1995-2000 para 34 dos 49 setores da indústria para os quais há informações sobre tarifas. Os dados de tarifa ef etiva são de Kume, Paani e Souza (op.cit.). 0 Quadro 3 mostra o índice $\mathrm{SI}_{\mathrm{A}}$ calculado para os 34 setores analisados.

\footnotetext{
${ }^{5}$ A Taxa de Câmbio R eal Efetiva espelha as variações no poder de compra da moeda brasileira com relação à moeda de seus principais parceiros comerciais e, portanto, se supõe que tenha mais influência nos fluxos de importação e exportação do país.
} 
Quadro 3: Índices $\mathrm{SI}_{\mathrm{A}}$ de 34 setores da indústria de transformação no período 1995-2000

\begin{tabular}{|c|c|c|c|c|c|c|}
\hline SETOR & 1995 & 1996 & 1997 & 1998 & 1999 & 2000 \\
\hline Siderurgia & $-1,82$ & 0,54 & $-1,00$ & $-1,19$ & 2,40 & $-0,61$ \\
\hline Metalurgia dos não-ferrosos & $-7,41$ & 2,71 & $-3,05$ & 0,05 & 3,57 & $-1,22$ \\
\hline Outros produtos metalúrgicos & $-2,65$ & $-2,67$ & $-2,78$ & 0,32 & 2,75 & 0,76 \\
\hline $\begin{array}{l}\text { Tratores e máquinas rodoviárias, } \\
\text { peças e acessórios }\end{array}$ & $-4,99$ & 1,37 & $-7,49$ & $-3,24$ & 5,44 & 1,36 \\
\hline $\begin{array}{l}\text { Condutores e outros materiais elétricos, } \\
\text { exclusive para veículos }\end{array}$ & $-1,34$ & $-4,13$ & $-7,64$ & $-4,51$ & 0,48 & $-1,72$ \\
\hline $\begin{array}{l}\text { Material e aparelhos eletrônicos } \\
\text { e de comunicação }\end{array}$ & $-8,34$ & $-2,83$ & $-6,10$ & $-8,69$ & $-5,14$ & $-2,28$ \\
\hline Automóveis, caminhões e ônibus & $-13,68$ & 12,52 & $-6,78$ & $-6,28$ & 11,97 & 0,26 \\
\hline Motores e peças para veículos & $-8,01$ & 0,06 & 2,39 & 8,33 & 13,49 & $-2,52$ \\
\hline Outros veículos & $-6,60$ & $-4,05$ & $-13,60$ & 2,48 & 2,38 & $-3,05$ \\
\hline Indústria da madeira & $-0,72$ & $-1,75$ & $-2,73$ & 0,89 & 3,74 & 0,10 \\
\hline Celulose e pasta mecânica & $-0,86$ & 0,14 & $-0,22$ & $-0,25$ & 0,24 & $-0,13$ \\
\hline Papel, papelão e artefatos de papel & $-10,71$ & 2,12 & $-0,48$ & $-1,22$ & 6,36 & $-0,18$ \\
\hline Indústria da borracha & $-6,65$ & 0,85 & $-2,29$ & $-0,73$ & 5,08 & $-0,60$ \\
\hline $\begin{array}{l}\text { Elementos químicos não-petroquímicos } \\
\text { ou carboquímicos }\end{array}$ & $-7,81$ & $-1,54$ & $-0,32$ & $-0,76$ & 4,93 & 3,05 \\
\hline Refino de petróleo & $-6,74$ & $-6,13$ & $-0,52$ & 4,47 & 0,76 & $-6,17$ \\
\hline Produtos químicos diversos & $-4,88$ & $-0,25$ & $-2,24$ & $-1,05$ & 1,54 & 0,10 \\
\hline Indústria farmacêutica & $-7,38$ & $-5,27$ & $-4,03$ & $-5,08$ & $-4,92$ & 3,68 \\
\hline Indústria de perfumaria, sabões e velas & $-1,89$ & 0,14 & $-0,83$ & $-0,47$ & 0,30 & 0,11 \\
\hline Laminados plásticos & $-1,96$ & 0,80 & 0,56 & $-0,35$ & 0,31 & $-0,30$ \\
\hline Artigos de material plástico & $-7,78$ & $-3,15$ & $-3,33$ & 0,60 & 1,64 & $-0,30$ \\
\hline $\begin{array}{l}\text { Beneficiamento, fiação e tecelagem } \\
\text { de fibras naturais }\end{array}$ & $-3,67$ & $-4,11$ & 0,71 & 4,76 & 3,65 & 1,19 \\
\hline $\begin{array}{l}\text { Fiação e tecelagem de fibras } \\
\text { artificiais ou sintéticas }\end{array}$ & $-7,24$ & 3,71 & $-0,94$ & $-0,01$ & 0,17 & $-2,25$ \\
\hline Outras indústrias têxteis & $-5,38$ & $-0,92$ & $-4,75$ & $-0,66$ & 2,10 & $-1,01$ \\
\hline Artigos do vestuário e acessórios & $-3,50$ & 0,12 & $-0,75$ & 0,82 & 2,15 & 0,20 \\
\hline Calçados & $-1,35$ & 0,31 & 0,00 & 1,02 & 0,67 & 1,12 \\
\hline Indústria do café & $-0,07$ & 0,01 & $-0,03$ & 0,07 & 10,01 & 0,00 \\
\hline Moagem de trigo & $-2,16$ & 11,47 & $-10,94$ & 2,40 & 1,22 & $-4,16$ \\
\hline $\begin{array}{l}\text { Conserva de frutas e legumes, } \\
\text { sucos e condimentos }\end{array}$ & $-1,12$ & 0,52 & $-0,35$ & 0,28 & 0,65 & 0,27 \\
\hline Abate de animais e preparação de carne & $-1,95$ & 3,54 & $-2,12$ & 1,40 & 5,39 & $-1,67$ \\
\hline Abate e preparação aves & $-0,03$ & 0,01 & $-0,02$ & 0,00 & 0,04 & $-0,01$ \\
\hline Resfriamento e preparação do leite e laticínios & $-4,05$ & 1,88 & 0,99 & $-0,70$ & 0,52 & 0,77 \\
\hline Indústria do açúcar & 0,14 & 0,15 & 0,18 & 0,04 & $-0,03$ & $-0,10$ \\
\hline $\begin{array}{l}\text { Refino de óleos vegetais e fabricação } \\
\text { de gordura para alimentação }\end{array}$ & $-2,58$ & $-3,72$ & 1,30 & $-1,93$ & 5,09 & 0,32 \\
\hline Outras indústrias alimentares & $-9,80$ & $-1,54$ & 1,89 & 0,67 & 6,44 & 1,04 \\
\hline
\end{tabular}

Fonte: elaboração própria a partir de dados de MOREIRA e PUGA (2001) 
Para a análise pretendida houve necessidade de conseguir os valores das tarifas para os anos de 1999 e 2000. Estes dados não estavam disponíveis, e foi necessário proceder-se a uma aproximação. Considerou-se, de forma arbitrária, que a estrutura da tarifa efetiva não teria sofrido alterações com relação ao último ano para o qual existem informações (1998).

A hipótese que está por trás desta simulação é a de que o processo de redução das tarifas estabilizou-se a partir de 1995 em grande parte dos setores, uma vez que segundo Kume, Piani e Souza (op. cit.), já em 1998 as variações das tarifas nominais com relações ao ano anterior (1997), quando ocorreram, foram muito pequenas.

Para processar essas informações procedemos a análise de tipo painel, como indicado a seguir.

\subsubsection{M odelos Estatísticos para D ados em Painel com U m Fator}

O bservações de uma variável resposta de interesse $y$, e de um vetor $x$ de variáveis explicativas para $\mathrm{N}$ diversos setores da economia em cada um de $\mathrm{T}$ sucessivos anos (t) constituem um conjunto de dados em painel. Diversos modelos de regressão linear têm sido propostos para este tipo de dados. De um modo geral, o modelo estabelece que, para um determinado setor $\mathrm{i}$, em um determinado tempo $t$, a resposta y $(i, t)$ está relacionada com os coeficientes ai , o vetor de variáveis $x(i, t)$ e pertubações al eatórias e $(i, t)$ segundo a expressão

$y(i, t)=a i+b(i)^{\prime} x(i, t)+e(i, t)$, para $i=1 . . N$.,$t=\ldots . . .(1)$

$O$ s diferentes modelos existentes na literatura correspondem a diferentes suposições sobre os coeficientes $A_{i}$, sobre os vetores de coeficientes $b(i)$ e sobre a distribuição dos termos al eatórios e(i,t), (Greene, 1997, p. 612). No presente trabalho admitiu-se que os diferentes setores podem possuir diferentes interceptos $a i$, mas que os coeficientes de regressão $b(i)$ relativos às variáveis $x$ (aqueles cuja estimação é o principal objetivo da análise de dados em painel) são os mesmos para os diversos setores (isto é $b(i)=b$ para $i=1 . . N$ ). Em outros termos, supôs-se que os diversos setores respondessem com a mesma velocidade a mudanças na tarifa e no câmbio, embora pudessem ter diferentes patamares iniciais de resposta. Este modelo é denominado "de efeitos fixos" de setores. Q uando - além de especificar que existe um intercepto diferente para cada setor - assume-se que a matriz de covariância das pertubações e(i,t) é diagonal e homocedástica, os coeficientes $a_{i}$ e b podem ser estimados pelo método de mínimos quadrados ordinários usando variáveis dummy para indicar os diversos setores. Se a matriz de covariância das pertubações e(i,t) for diagonal mas heterocedástica, os coeficientes ai e $b$ ainda podem ser estimados pelo método de mínimos quadrados, mas é necessário que se faça uma estimação robusta da matriz de covariância dos estimadores de b, por exemplo através da matriz de W hite (Greene, 1997, p.635).

D esta forma, foi utilizado o modelo de ef eitos fixos para dados em painel para fazer inferências acerca dos efeitos de tarifa e câmbio sobre o índice de substituições de importação $\mathrm{SI}_{\mathrm{A}}$ para o universo dos 34 setores da indústria estuda- 
dos. A pós ajustar um modelo com efeitos fixos diferentes para cada setor, é feito um teste sobre a hipótese $\mathrm{H}_{0}$ de igualdade das constantes $\mathrm{a}_{\mathrm{i}}$. Se $\mathrm{o}$ teste levar à aceitação de $\mathrm{H}_{0}$, 0 modelo final será um $\mathrm{M}$ odelo de Regressão com o mesmo intercepto básico, $y(i, t)=a+b x(i, t)+e(i, t)$.

\section{RESULTADOS}

A mudança brusca observada no patamar da variável câmbio em 1999 provavelmente alterou o seu efeito sobre o índice de substituição de importações $\left(\mathrm{SI}_{\mathrm{A}}\right)$, o que levou à decisão de analisar separadamente os períodos 1995-1998 e 1999-2000. O s modelos ajustados serão designados por R egressão I e R egressão II , respectivamente.

Para o primeiro período de análise (1995-1998), os efeitos de setores foram significativos. As estimativas dos efeitos fixos $a_{i}(i=1 \ldots 34)$ referentes a cada um dos 34 setores analisados encontram-se no Q uadro 4, sendo que a média dessas estimativas foi $-68,04$.

Quadro 4: Estimativas dos efeitos fixos de setores $\left(a_{i}\right)$ na Regressão I

\begin{tabular}{llccc}
\hline \multicolumn{1}{c}{ SETOR } & EFEITO & D. P. & t \\
\hline 1 & Siderurgia & $-65,24$ & 10,78 & $-6,05$ \\
\hline 2 & Metalurgia dos não-ferrosos & $-65,92$ & 10,79 & $-6,11$ \\
\hline 3 & Outros produtos metalúrgicos & $-68,68$ & 10,75 & $-6,39$ \\
\hline 4 & Tratores e máquinas rodoviárias, inclusive peças e acessórios & $-69,20$ & 10,76 & $-6,43$ \\
\hline 5 & Condutores e outros materiais elétricos, exclusive para veículos & $-71,71$ & 10,75 & $-6,67$ \\
\hline 6 & Material e aparelho eletrônico e de comunicação & $-72,23$ & 10,76 & $-6,71$ \\
\hline 7 & Automóveis, caminhões e ônibus & $-99,47$ & 11,06 & $-8,99$ \\
\hline 8 & Motores e peças para veículos & $-65,43$ & 10,76 & $-6,08$ \\
\hline 9 & Fabricação de outros veículos & $-72,81$ & 10,76 & $-6,77$ \\
\hline 10 & Indústria da madeira & $-65,71$ & 10,78 & $-6,10$ \\
\hline 11 & Celulose e pasta mecânica & $-64,71$ & 10,78 & $-6,00$ \\
\hline 12 & Papel, papelão e artefatos de papel & $-66,98$ & 10,78 & $-6,21$ \\
\hline 13 & Indústria da borracha & $-67,24$ & 10,77 & $-6,24$ \\
\hline 14 & Elementos químicos não-petroquímicos ou carboquímicos & $-67,30$ & 10,78 & $-6,25$ \\
\hline 15 & Refino de petróleo & $-65,01$ & 10,80 & $-6,02$ \\
\hline 16 & Produtos químicos diversos & $-66,18$ & 10,78 & $-6,14$ \\
\hline 17 & Indústria farmacêutica & $-69,06$ & 10,79 & $-6,40$ \\
\hline 18 & Indústria de perfumaria, sabões e velas & $-64,38$ & 10,79 & $-5,97$ \\
\hline 19 & Laminados plásticos & $-66,50$ & 10,76 & $-6,18$ \\
\hline
\end{tabular}




\begin{tabular}{llrrr}
\hline 20 & Artigos de material plástico & $-69,68$ & 10,76 & $-6,48$ \\
\hline 21 & Beneficiamento, fiação e tecelagem de fibras naturais & $-67,34$ & 10,75 & $-6,26$ \\
\hline 22 & Fiação e tecelagem de fibras artificiais ou sintéticas & $-67,89$ & 10,75 & $-6,31$ \\
\hline 23 & Outras indústrias têxteis & $-69,69$ & 10,75 & $-6,48$ \\
\hline 24 & Artigos do vestuário e acessórios & $-67,88$ & 10,75 & $-6,32$ \\
\hline 25 & Calçados & $-66,17$ & 10,76 & $-6,15$ \\
\hline 26 & Indústria do café & $-64,62$ & 10,78 & $-6,00$ \\
\hline 27 & Moagem de trigo & $-65,63$ & 10,76 & $-6,10$ \\
\hline 28 & Conserva de frutas e legumes, inclusive sucos e condimentos & $-65,99$ & 10,76 & $-6,13$ \\
\hline 29 & Abate de animais e preparo de carnes & $-63,78$ & 10,79 & $-5,91$ \\
\hline 30 & Abate e preparação aves & $-64,01$ & 10,79 & $-5,93$ \\
\hline 31 & Resfriamento e preparação do leite e laticínios & $-66,78$ & 10,76 & $-6,21$ \\
\hline 32 & Indústria do açúcar & $-65,56$ & 10,76 & $-6,09$ \\
\hline 33 & Refino de óleos vegetais e fabricação de gorduras para alimentação & $-65,63$ & 10,79 & $-6,08$ \\
\hline 34 & Outras indústrias alimentares & $-68,79$ & 10,75 & $-6,40$ \\
\hline
\end{tabular}

MÉDIA DAS ESTIMATIVAS DOS EFEITOS FIXOS DOS SETORES $=-68,04$

As observações apresentaram heterogeneidade, de modo que a matriz de covariância apropriada foi estimada pela matriz de W hite e 0 valor de $R^{2}$ foi 0,51 .

A T abela 1 apresenta as estimativas dos coeficientes de R egressão I (19951998) para as variáveis explicativas.

Tabela 1: -Estimativas dos parâmetros da Regressão I, estatística t e nível de significância (P)

\begin{tabular}{cccccc}
\hline Variável & Coeficiente & Estimativa & D.P. ${ }^{1}$ & $\mathrm{t}_{0}$ & $\mathrm{P}\left[\mathrm{t}>\mathrm{t}_{0}\right]$ \\
\hline Tarifa & $\mathrm{b}_{1}$ & 0,2143 & 0,0270 & 7,943 & 0,0000 \\
\hline Câmbio & $\mathrm{b}_{2}$ & 0,6341 & 0,1099 & 5,770 & 0,0000 \\
\hline
\end{tabular}

1 - Desvio Padrão obtido a partir da matriz de covariância de White.

Segundo a Tabela 1, verifica-se que os coeficientes relativos à tarifa e câmbio são ambos positivos e significativos.

$\mathrm{O}$ modelo final ajustado $\mathrm{SI}_{\mathrm{A}}$ depende de efeitos fixos específicos para os setores, da tarifa e do câmbio, isto é :

$\mathrm{SI}_{A}(i, t)=a_{i}+0,2143$ Tarifa $+0,6341$ Câmbio $+e(i, t)$.

No período 1999-2000 (R egressão II), o efeito de setores não foi significativo, de modo que no modelo final ajustado $\mathrm{SI}_{\mathrm{A}}$ só depende de um intercepto a comum a todos os setores e das variáveis explicativas Tarifa e Câmbio.

A Tabela 2 apresenta as estimativas dos coeficientes da R egressão II para as variáveis explicativas. 0 valor de $\mathrm{R}^{2}$ foi de 0,2923 . 
Tabela 2: Estimativas dos parâmetros da Regressão Il, estatística t e nível de significância (P)

\begin{tabular}{cccccc}
\hline Variável & Coeficiente & Estimativa & D.P. ${ }^{1}$ & t0 & P[|t $\left.>\mathrm{t}_{0}\right]$ \\
\hline Tarifa & $\mathrm{b}_{1}$ & 0,0486 & 0,0174 & 2,801 & 0,0067 \\
\hline Câmbio & $\mathrm{b}_{2}$ & 0,3207 & 0,0736 & 4,358 & 0,0000 \\
\hline Intercepto & $\mathrm{A}$ & 35,8650 & 8,2425 & $-4,351$ & 0,0000 \\
\hline
\end{tabular}

1 - obtido a partir da matriz de covariância de White

Como mostra a Tabela 2, o intercepto a e os coeficientes relativos à Tarifa e Câmbio são significativos no segundo período (R egressão II).

Assim, o modelo ajustado (R egressão II) foi:

$\mathrm{SI}_{A}(\mathrm{i}, \mathrm{t})=35,8650+0,0486 \mathrm{~T}$ arifa +0,3207Câmbio +e(i,t).

Comparando-se a Tabela 1 com a Tabela 2, percebe-se que os coeficientes das variáveis explicativas Tarifa e Câmbio diminuíram no segundo período, bem como $0 R^{2}$ da regressão, que passou de 0,5081 para 0,2923. Há indicações, portanto, de que outras variáveis, além das consideradas neste trabalho, tenham passado a interferir de forma mais significativa no comportamento de $\mathrm{SI}_{A}$ no segundo período.

\subsection{Análise da influência das variáveis explicativas tarifa efetiva e câmbio sobre o índice de substituição de importações}

A simples inspeção dos coeficientes de regressão estimados após um ajuste de um modelo não é suficiente para determinar qual das variáveis explicativas provoca maior variação na variável resposta. Isso se deve à diferença existente entre as distribuições das variáveis explicativas, que pode ser evidenciada pelas informações contidas na Tabela 3, quanto ao valor da média, desvio padrão e média mais meio desvio padrão das variáveis explicativas Tarifa e Câmbio, para o conjunto de dados utilizados na R egressão I.

Tabela 3: Medidas resumo da distribuição da Tarifa efetiva e do câmbio na Regressão I

\begin{tabular}{lcc}
\hline & Tarifa & Câmbio \\
\hline Média & 20,89 & 97,40 \\
\hline Desvio Padrão & 25,89 & 2,13 \\
\hline Média + 0,5 Desvio Padrão & 33,84 & 98,47 \\
\hline
\end{tabular}

A Tabela 4 apresenta as mesmas informações de acordo com os dados utilizados na R egressão II. 
Tabela 4: Medidas resumo da distribuição da Tarifa efetiva e do câmbio na Regressão I I

\begin{tabular}{lcc}
\hline & Tarifa & Câmbio \\
\hline Média & 21,49 & 111,80 \\
\hline Desvio Padrão & 19,65 & 4,63 \\
\hline Média + 0,5 Desvio Padrão & 31,31 & 114,12 \\
\hline
\end{tabular}

A partir dos parâmetros estimados nas R egressões I ell para as variáveis Tarifa e Câmbio (tabelas 2 e 3 ) e dos valores da média e desvio padrão destas variáveis nos os períodos 1995-1998 e 1999- 2000 (tabelas 4 e 5), foi calculado 0 valor do índice $\mathrm{SI}_{\mathrm{A}}$ predito.

De acordo com a R egressão I, para valores de Tarifa efetiva e Câmbio iguais aos respectivos valores médios no período, o valor de $\mathrm{SI}_{\mathrm{A}}$ predito foi calculado como sendo -1,7951. A o se aumentar o valor da média da tarifa em meio desvio padrão, mantendo-se o valor do câmbio fixo em sua média, o $\mathrm{SI}_{\mathrm{A}}$ predito alterase para 0,9782. A o se aumentar o valor da média do câmbio em meio desvio padrão, mantendo-se 0 valor da tarifa fixo em sua média, $0 \mathrm{SI}_{A}$ predito altera-se para -1,118. Portanto, de acordo com a R egressão I, que diz respeito aos dados para o primeiro período analisado (1995-1998), a variável tarifa efetiva (Tarifa) exerceu maior influência nas variações do índice $\mathrm{SI}_{\mathrm{A}}$ do que a variável Câmbio. A Tabela 5 resume estas informações.

Tabela 5: Índice SIA predito na Regressão I para valores selecionados das variáveis explicativas Tarifa Efetiva (A) e Câmbio (B), no período 1995-1998*

\begin{tabular}{llc}
\hline \multicolumn{1}{c}{$A$} & \multicolumn{1}{c}{$B$} & Índice $\mathrm{SI}_{\mathrm{A}}$ Predito \\
\hline$M_{\text {TARIFA }}$ & $M_{\text {CÂMBIO }}$ & $-1,7951$ \\
\hline$M_{\text {TARIFA }}+0,5 D_{\text {TARIFA }}$ & $M_{\text {CÂMBIO }}$ & 0,9782 \\
\hline$M_{\text {TARIFA }}$ & $M_{\text {CÂMBIO }}+0,5 D_{\text {CÂMBIO }}$ & $-1,118$ \\
\hline$M=$ Média; DP = desvio padrão & &
\end{tabular}

Q uando se considera a R egressão II o índice de $\mathrm{SI}_{\mathrm{A}}$ predito, com base nos valores da média de tarifa e câmbio para o período (Tabela 4), foi 1,034. A o se aumentar o valor da média da tarifa em meio desvio padrão, mantendo-se o vaIor do câmbio fixo em sua média, o $\mathrm{SI}_{\mathrm{A}}$ predito altera-se para 1,511. A o se aumentar o valor da média do câmbio em meio desvio padrão, mantendo-se 0 valor da tarifa fixo em sua média, $0 \mathrm{SI}_{\mathrm{A}}$ predito altera-se para 1,7803. Portanto, de acordo com a Regressão II, ou seja, no período 1999-2000, a variável câmbio exerceu maior influência nas variações do índice $\mathrm{SI}_{\mathrm{A}}$ que a variável tarifa efetiva. A Tabela 6 resume estas informações. 
Tabela 6: Índice SIA predito na Regressão II para valores selecionados das variáveis explicativas Tarifa Efetiva (A) e Câmbio (B), no período 1999-2000*

\begin{tabular}{llc}
\hline \multicolumn{1}{c}{$A$} & \multicolumn{1}{c}{$B$} & Índice $\mathrm{SI}_{\mathrm{A}}$ Predito \\
\hline $\mathrm{M}_{\text {TARIFA }}$ & $\mathrm{M}_{\text {CÂMBIO }}$ & 1,034 \\
\hline$M_{\text {TARIFA }}+0,5 \mathrm{DP}_{\text {TARIFA }}$ & $M_{\text {CÂMBIO }}$ & 1,511 \\
\hline$M_{\text {TARIFA }}$ & $M_{\text {CÂMBIO }}+0,5 D_{\text {CÂMBIO }}$ & 1,7803 \\
\hline
\end{tabular}

* M = Média; DP = desvio padrão

O s resultados obtidos nestas análises mostram que as variações nas tarifas efetivas e no câmbio exerceram efeito sobre o índice $\mathrm{Sl}_{\mathrm{A}}$ em todo o período analisado (1995-2000), e SI A se mostrou uma função crescente tanto do câmbio quanto do nível da tarifa efetiva nos 34 setores da indústria de transformação estudados. Porém, no intervalo estudado anterior à desvalorização (1995-1998) as oscilações intersetoriais no índice $\mathrm{SI}_{\mathrm{A}}$ se deveram mais às oscilações intersetoriais no nível das tarifas efetivas dos setores. Já no intervalo pós desvalorização cambial (1999-2000), o câmbio foi o maior responsável pelas variações nos índices $\mathrm{SI}_{A}$. Este resultado significa que, se o intervalo 1995-1998 foi o período de maior estabilidade nas tarifas nominais e efetivas observado na última década, e isto se prolongou até 0 ano 2000, a variação cambial a partir de janeiro de 1999 foi a maior responsável pela substituição de importações observada nesses setores em 1999 e 2000 com relação ao ano de 1998.

Portanto, pode-se dizer que no período 1995-1998 a substituição de importações foi induzida pela preservação de níveis de tarifa significativos (apesar do esforço de abertura comercial) e algum grau de dispersão da estrutura tarifária, o que resultou na manutenção de níveis expressivos de proteção efetiva. Já após 1999 a magnitude da desvalorização cambial foi tal que o efeito preços relativos superou a proteção como elemento indutor. Prova disso é que em 2000, com a revalorização do Real, houve uma redução do ritmo de $\mathrm{SI}_{\mathrm{A}}$.

\section{CONCLUSÕES}

N este trabalho procurou-se avaliar através de uma análise de regressão a influência da tarifa efetiva e da taxa de câmbio efetiva real no índice de substituição de importações $\mathrm{SI}_{\mathrm{A}}$, no período 1995-2000. A análise mostra que as duas variáveis tiveram efeito significativo sobre a variação do índice $\mathrm{SI}_{A}$ e que, a partir de 1999, o efeito do câmbio ef etivo real mostrou-se mais importante que o da tarifa efetiva, uma vez que depois de 1998 as tarifas nominais e efetivas variaram muito pouco e o câmbio sofreu grande depreciação em janeiro de 1999. Este fato sugere que o processo de substituição de importações tenha sido mais provavelmente "natural" ou "espontâneo" do que "induzido" no período recente.

Esse resultado é importante, porque ressalta a relevância - para os setores produtivos - de poder contar com preços relativos ajustados. É essa maior transparência dos sinais de mercado que permite a uma economia explorar suas vantagens comparativas de modo eficiente, como ensina a teoria de comércio internacional. 


\section{REFERÊN CIAS BIBLIOGRÁFICAS}

ALEM , A. C.; BARROS, J. R. M .; GIAM BIAGI, F. Bases para uma política industrial moderna. In: Fórum $\mathrm{N}$ acional Rio de Janeiro, 14, 2002, Rio de Janeiro. Estudos e Pesquisas $\mathrm{n} 022$. Disponível em: বhttp://www.forumnacional.org.br/publi/pestpq1.asp>. A cesso em 9 de set. 2002. (Texto a ser publicado)

BARROS, J. R. M .; GOLDEN STEIN , L. A valiação do processo de reestruturação industrial brasileiro. In: Revista de Economia Política, v. 17, no 2 (66), p. 11- 31, abr./jun. 1997.

BAUM AN N R.; RIVERO J.; ZAVATTIERO Y. As tarifas de importação no Plano R eal. In: Pesquisa e Planejamento E conômico , IPEA, v. 27, № 3, dez. 1997

BOLETIM FUN CEX DE CÂM BIO. Rio de Janeiro: Fundação Centro de Estudos do Comércio Exterior, A no VII, no 10, nov./dez. 1998.

BOLETIM FUN CEX DE CÂM BIO. Rio de Janeiro: Fundação Centro de Estudos do Comércio Exterior, A no XII, no 2, fev. 2002.

BRUTON, H. Import substitution. In: CHENERY, H.; SRIN IVASAN, T.N . (Eds.). H andbook of international economics. Amsterdam: $\mathrm{N}$ orth $\mathrm{H}$ oland, 1989. v. 2, p. 1.602-1.643.

DESAI, P. A Iternative measures of import substitution. O xford E conomic Papers. v. 21, no 3, 1969. p. 312-324.

DIAZ-ALEJANDRO, C. F. Trade, policies and economic development. In: KEN EN , P. (Ed.). International trade and finance: frontiers for research, Cambridge: Cambridge University, 1975. p. 93150.

GREEN E, W. H. Econometric analysis. $3^{\text {rd }}$ ed. [s.I.]: Prentice H all, 1997.

KUM E, H.; PIAN I, G.; SOUZA, C. F. B. A política brasileira no período 1987-98: descrição e avaliação. 2a versão. IPEA-DIM AC. Rio de Janeiro: IPEA, maio 2000. (Texto não publicado)

LEVY, P. M .; SERRA, M . I. F. Coeficientes de importação e exportação na indústria. In: IPEA Boletim de Conjuntura, № 58, jul./ago. 2002 p. 65-80.

M ELO, P. R.S.; RIOS, E. C. S. D.; GUTIERREZ, R. M. V. Componentes eletrônicos: perspectivas para o Brasil. BN DES Setorial. Rio de Janeiro: BN DES, no 13, mar. 2001 p. 3-64.

M OREIRA, M. M .; PUGA, F. P. Coeficientes de comércio em 2000: 0 desafio externo. N ota técnica AP/DEPEC no 04/2001. Rio de Janeiro: BN DES, mai. 2001.

TAVARES, M .C. Auge e declínio do processo de substituição de importações no Brasil. In: TAVA RES, M .C. D a substituição de importações ao capitalismo financeiro. 6a ed. Rio de Janeiro: Zahar, 1977. p. 29-124.

Figura 1: Tarifa Efetiva Média: 1987-1998 (em \%)

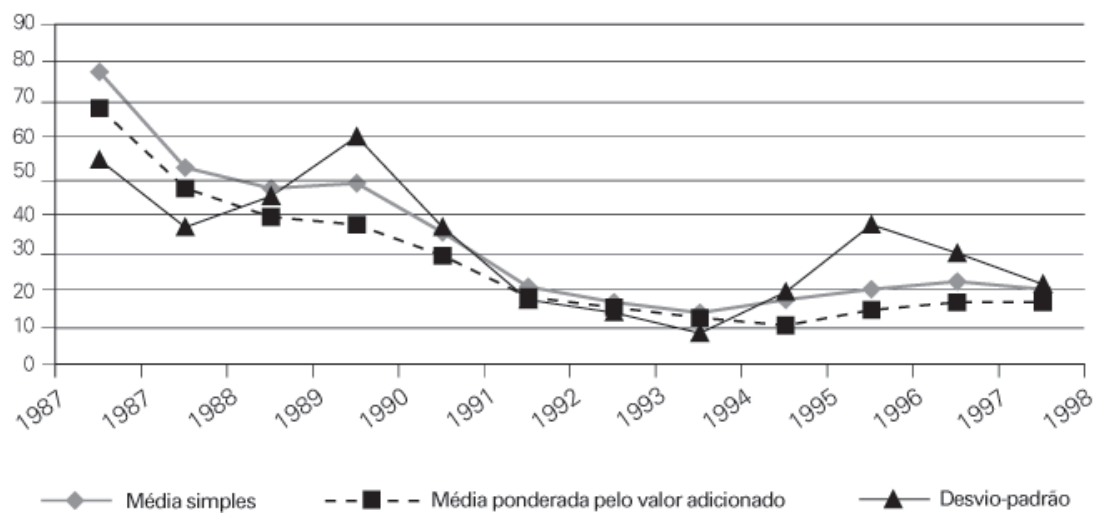

Fonte: Elaboração própria a partir de dados de Kume, Piani e Souza (2000, p. 17). 